\title{
BIDRAG TILL EN FIKTIONOLOGISK EPISTEMOLOGI
}

A CONTRIBUTION TO NARRATIVE EPISTEMOLOGY | In the wake of Roman Ingarden's

Das Literarische Kunstwerk many literary theorists have claimed that fictional worlds are "incomplete", contrary to our real world. This idea is critically examined; the conclusion of the examination is that in most cases the incompleteness thesis is based on confusion between ontology and epistemology. However, in some cases - one example is Kafka's The Process - the thesis is better warranted, but in these cases incompleteness may just as well be described in semantic terms as vagueness.

KEYWORDS I Incompleteness, fictional epistemology, fictional ontology, unreliable narrator, Roman Ingarden, Petr Kotatko

I den här artikeln vill jag diskutera problem i samband med vad som ibland kallas "fiktionell ofullständighet", det vill säga frågan huruvida fiktiva världar till skillnad från vår aktuella värld - eller "verkligheten” som den vanligen kallas - kan vara så beskaffade att en rad påståenden om de händelser, ting och varelser de rymmer varken är sanna eller falska. ${ }^{I}$ Ytterst rör denna diskussion fiktionsberättelsens ontologi och epistemologi, vad som existerar i en viss fiktionsvärld, och hur vi når kunskap om dess innehåll. Avslutningsvis kommer jag att beröra frågan om hur mina slutsatser förhåller sig till vad jag vill kalla "narrativ omedelbarhet" - den citerade termen får sin förklaring i det sammanhanget.

Roman Ingarden har i Das Literarische Kunstwerk från I93I formulerat det förmodade faktum att fiktiva världar till skillnad från vår verkliga värld är ofullständiga. Hans exempel är ett bord omnämnt i en hypotetisk roman. Vilket material bordet är tillverkat av nämns inte, och följaktligen består inte bordet av något särskilt

I Språkbruket här och i resten av artikeln kan verka besynnerligt. Jag talar om "sanningar", "övertygelser", "kunskap", "epistemologi" och så vidare och syftar med dessa ord på karaktärer, ting och tilldragelser i fiktionsberättelser, det vill säga sådant som ofta kännetecknas av att inte vara sant eller föremål för tro eller kunskap. Det är emellertid i det närmaste ofrånkomligt att inte använda ett sådana termer om fiktioner: vi säger att Hamlet är melankolisk, att vi är övertygade om att han är det, att påståendet är han är en glad och lättsam typ är osant och så vidare. Detta bruk av epistemiska och doxastiska termer är visserligen figurativt men inte desto mindre grundläggande. 
material. Ingarden kallar sådana ofullständigheter "Leerstellen", "tomma ställen", och han karakteriserar dem i motsättning till verkliga förhållanden: "Hos ett realt föremål är [---] sådana tomma ställen icke möjliga. På sin höjd kan materialet vara obekant.” (326) Enligt Ingarden är således fiktiv ofullständighet ett ontologiskt fenomen, i verkligheten är ofullständighet "på sin höjd" en epistemisk företeelse.

Efter Ingarden har diskussionen om fiktiv ofullständighet stimulerats och förfinats av inflytanden från möjlig värld-semantik på litteraturvetenskaplig teori. Lubomir Dolezel har inom denna ram förfäktat tesen om fiktiva världars ofullständighet, medan Marie-Laure Ryan (Possible Worlds, Artificial Intelligence) med samma teoretiska utgångspunkter har argumenterat mot att denna tes skulle vara generellt giltig. ${ }^{2}$ För båda spelar David Lewis artikel "Truth in Fiction" från 1978 en avgörande roll. I förenklad form innebär Lewis' hållning till fiktiv ofullständighet följande. Det finns (åtminstone) två principer som är relevanta för frågan vad som är sant $\mathrm{i}$ en viss fiktiv värld. Den ena är rotad i vår aktuella värld, den andra i de gemensamma övertygelser som råder eller rått i det samhälle där det fiktionella verket skapats. För att avgöra vilket material bordet $i$ Ingardens exempel är tillverkat av, ställer vi oss antingen frågan hur verkligheten skulle vara beskaffad om historien berättades som en faktiskt sann berättelse, inte en fiktionsberättelse, eller, i enlighet med den andra principen, vad utfallet skulle bli om vi antoge att berättelsen vore sann mot bakgrund av delade övertygelser i författarens tid och samhälle, en bakgrund som vi även den antar är sann. Vi inser genast att vi i det senare fallet skulle få möjliga världar med "Leerstellen". Många frågor lämnas obesvarade av de delade övertygelser som råder i ett samhälle vilket som helst, och när dessa vita kunskapsfläckar inte heller klaras ut av berättelsen har vi tomma ställen i Ingardens mening. Men även det första alternativet - vi läser fiktionsberättelsen mot bakgrund av vad som faktiskt är sant - ger utrymme för "Leerstellen". Om den berättande texten vore sann så är det ungefär lika troligt att bordet skulle vara gjort av björk som av furu. Frågan lämnas alltså $\mathrm{i}$ både fallen obesvarad.

I logiska termer leder detta till en anomali. Om vi antar att klassen björkmöbler (i betydelsen möbler tillverkade endast av björk) och furumöbler (i motsvarande betydelse) är ömsesidigt uteslutande så följer att den möjliga värld som vi läser in i Ingardens tänkta roman varken innehåller sanningen "Bordet $\mathrm{x}$ är tillverkat av björk" eller sanningen "Bordet $\mathrm{x}$ är inte tillverkat av björk".

Kendall Walton kallar de två principer som hos honom motsvarar Lewis par för "the Reality Principle" och "the Mutual Belief Principle" (I44-I6I). I likhet med Lewis betonar Walton att det resultat som den ena principen ger kan motsäga resultatet av en tillämpning av den andra principen. En annan likhet med Lewis idéer är den att båda principerna är i samklang med tesen om fiktiva världars ofullständighet. Walton illustrerar hur de två principerna fungerar med ett exempel. En läsare, Loretta, läser en fiktionsberättelse om en man, Andy, som uppträder

2 För en exposé över tillämpningar i narratologi och fiktionsteori av möjlig-värld semantik, se Ryans "PossibleWorlds Theory"! 
på ett visst anti-socialt vis. Efter att ha studerat modern medicinsk litteratur drar Loretta slutsatsen att Andy lider av en viss medfödd neurologisk sjukdom. Mabel läser samma bok men upprättar sin epistemiska bakgrund genom att konsultera historiska arkiv. Dessa studier ger vid handen att Andy - enligt med verket samtida föreställningar - är besatt av djävulen. Loretta tillämpar verklighetsprincipen, medan Mabel tillämpar principen om delad övertygelse (I59-I60, I67). En läxa av detta är den att vad som är sant i en viss fiktion kan skifta. En annan är att när såväl bakgrunderna som den berättande texten lämnar osagt vilket sakförhållande som råder, till exempel vilket material ett viss bord är tillverkat av, så har vi, förefaller det, "Leerstellen". Waltons exempel kan dessutom tjänstgöra som illustration till att "sanning", "övertygelse" och "kunskap" i dessa fiktionella sammanhang alltid gäller relativt en viss läsning - såväl Mabels som Lorettas läsning genererar kunskap, trots oförenligheten.

Filosofen Petr Kotatko diskuterar i en artikel kritiskt frågan huruvida detta verkligen innebär att narrativ fiktion är ofullständig. Hans exempel är Balzacs roman Splendeurs et misères des courtisanes. Kotatko skriver: "Was Mme d'Espard's gall bladder [vid en viss tidpunkt] in good condition?” (97) Då ingenting påstås eller underförstås om tillståndet för hennes gallblåsa, och då varken verklighetsprincipen eller principen om delad övertygelse fäller något utslag, utesluts båda förmodandena från fiktionsvärlden, detta i samklang med tesen om ofullständighet. Det är varken fallet att madame d'Espards gallblåsa är i gott tillstånd eller att den inte är i gott tillstånd. Kotatko konkluderar: "A novel whose world would be inhabited by such bizarre creatures ought to aspire to some genre rather different from 'scenes from a Parisian life'.” (97)

Jag instämmer. Tanken att fiktiva världar bebos av ofullständiga varelser är absurd. Vår kunskap om dem är ofullständig men de är inte själva inkompletta. Ofullständigheten är epistemisk, inte ontologisk. Eller, med Petr Kotatkos ord: "It is right to say that our construction of the character is incomplete - but the incomplete construction of a character is something very different from the contruction of an incomplete character." (99)

Kotatko hänvisar i artikeln till realistiska romaner från I8oo-talet, romaner av Stendahl, Tolstoj och, framför allt, Balzac, men i en avslutande kommentar antyds att han inte menar att denna kritik kan riktas mot all fiktionell romankonst: "To give up this assumption [om ofullständighet] means to start reading the Splendeurs as one of the novels of Beckett's Trilogy.” (99) Fiktiva världar sprungna ur viss modern fiktionslitteratur kan alltså med rätta, förefaller det, uppfattas som ofullständiga. Jag återkommer strax till det.

Ett problem som inte tas upp av Kotatko är följande: varför behandlar så många litteraturteoretiker fiktionella och faktuella framställningar så olika vad gäller frågan om ofullständighet. Ingardens formulering lyder som sagt: ”Hos ett realt föremål är [---] sådana tomma ställen icke möjliga. På sin höjd kan materialet vara 
obekant.” Varför inte bara göra gällande detsamma för fakta och fiktion, att läsaren inte har kunskap om vilket material ett visst bord är tillverkat av? Om Kotatko har rätt i sin kritik kräver denna fråga ett svar.

Mitt första - och preliminära - svar lyder: vi talar om ofullständighet därför att det föreligger en kunskapsmässig skillnad mellan fiktion och fakta, en annan skillnad än den uppenbara att fiktionens kunskap är - fiktiv. Vi kan av olika anledningar veta att en sats i en faktatext är sann eller att den är falsk. Vi kan med egna ögon se att bordet är tillverkat av björk, eller att det inte är det, vi kan komma till en övertygande slutsats från andra källor än den lästa texten att det är på det ena eller andra viset. Men vi erkänner fiktionstexten som sann av ett enda skäl: texten säger det. Om vi önskar pröva sanningshalten i en faktatext söker vi upp andra, mer tillförlitliga, källor, och detta kan innebära att vi förkastar eller reviderar den information vi fått. Vi skiljer klart och tydligt på vår förståelse av texten och vårt försanthållande. Vår förståelse av en fiktionsberättelse sammanfaller med, och är rentav identiskt med, vad vi uppfattar som sann information. Fiktionsläsaren är i den högst anmärkningsvärda situationen att få ta del av "hela sanningen och ingenting annat sanningen", ett privilegium vi aldrig åtnjuter utanför fiktionsläsningens värld. Denna intima relation mellan förståelse och sanning har konsekvenser för vår upplevelse av fullständighet och ofullständighet. När vi läst ut Ingardens tänkta berättelse finns det i princip inget sätt att få reda på vilket material det nämnda bordet är tillverkat av. När vi läser samma mening i en faktatext kan det vara svårt och rentav i praktiken omöjligt få besked om materialet, men det är inte i princip omöjligt. Ett tillförlitligt dokument kan dyka upp, till exempel en räkning från en möbelsnickare, som ger vid handen att bordet är av björk. Uttryckt på ett annat sätt: förståelsen av en fiktionell berättelse och vad som är sant i fiktionen är två kategorier som kommer varandra så nära att gränsen mellan epistemologi och ontologi förefaller i det närmaste upphävd. Läsaren (och teoretikern) faller offer för illusionen att de båda filosofiska kategorierna sammanfaller.

Som jag påpekat antyder Kotatko emellertid att viss modernistisk prosa verkligen är ontologiskt ofullständig. Är detta riktigt? Han anför Samuel Becketts romantrilogi, men jag tror att Franz Kafkas Der Prozess lika gott kan tjänstgöra som exempel. Enligt den vanligaste uppfattningen i forskningen och även bland romanens fiktiva karaktärer så arresteras huvudpersonen Josef K. i bokens första kapitel. Men hur skildras själva arresteringen? Ingenting annat än en viss replik fälld av en rättslig tjänsteman ger sken av ett arresteringsförfarande: "Ni är ju arresterad!" ["Sie sind ja verhaftet!"] Men detta är ju snarare ett uttryck för övertygelsen att Josef K. redan blivit arresterad än den performativa fras vi förväntar oss - "ni är arresterad" eller "ni är härmed arresterad". Dessa iakttagelser kan utvecklas till en tolkning enligt vilken det varken är sant eller osant att Josef K. arresteras. I semantiska termer är "arrestering”, termen och företeelsen, så pass vag i romanens värld att det existerar fall, som Josef Ks, som faller mellan de två varandra uteslutande möjligheterna. Tolkningen kan tänkas utvecklad till att omfatta en rad rättsliga kategorier i romanen. Men en snarlik men något annorlunda möjlighet kan illus- 
treras av det juridiska förloppets slutpunkt, Josef Ks död. En vanlig uppfattning bland kommentatorer är att $\mathrm{K}$. befunnits skyldig av domstolen och därför avrättas. Men Lubomir Dolezel pekar på flera omständigheter som tyder på att vi inte bevittnar en legal avrättning utan kort och gott en slakt utan förklaring (I95-I96). En möjlig tolkningsväg skulle kunna vara att påvisa dels övertygande evidens $i$ texten för att Josef K. avrättas, dels lika övertygande evidens för att så inte är fallet, med slutsatsen att Josef $\mathrm{K}$. både avrättas och inte avrättas. Naturligtvis kan ett liknande resonemang, ändande i en logisk motsägelse, mobiliseras i det första fallet, om arrestering, och en argumentation för den motsägelsefulla avlivningen av K. skulle kunna vändas till ett resonemang för tesen även denna passage är vag med konsekvensen att Josef $\mathrm{K}$. varken blir avrättad eller inte avrättad.

Detta exempel skiljer sig på en rad punkter från såväl Ingardens bord som madame d'Espards gallblåsa. Dessa senare båda fall tilldrar sig ingen spontan uppmärksamhet - först när litteraturteoretikern påpekar problemet uppstår det för läsaren. Och det finns ingenting i skildringarna som ger möjlighet till en näraliggande tolkning vilken skulle mynna i en uppenbar motsägelse, och, slutligen, lakunerna saknar helt betydelse för våra helhetstolkningar. Kafkas ofullständigheter däremot stirrar läsaren i ansiktet, de kan med små justeringar omtolkas som logiska motsägelser, och de är i högsta grad tolkningsmässigt signifikanta. Men den springande punkten är en annan: är det mer motiverat att beteckna arresteringen/ icke-arresteringen i första kapitlet av Der Prozess som ett exempel på ontologisk ofullständighet? Kotatko pekar på en omständighet som kan anföras här. Han menar att även om vi - det vill säga läsarna - inte kan få besked om madame d'Espards gallblåsa så är sådan kunskap hypotetiskt möjlig (97-98). Om en läkare modernt utbildad med inriktning på kirurgi och inre medicin och modernt utrustad med ultraljudsapparatur skulle undersöka madame d'Espard, så skulle denna läkare med största sannolikhet kunna ställa en hygglig diagnos på hennes gallblåsa. Balzacs värld är i detta avseende konstruerad som vår verklighet. Tillämpar vi detta resonemang på det första kapitlet i Der Prozess så kan vi meningsfullt argumentera för att ingen kontrafaktisk procedur skulle kunna fastställa om Josef K. arresteras eller ej. Det skulle vara lika fåfängt som att försöka finna hypotetiska metoder att fastställa om en viss gleshårig person är skallig eller ej. Ett sådant epistemologiskt läge motiverar i betydligt högre grad klivet över i ontologin: $K$. är varken arresterad eller inte arresterad, liksom vissa personer varken är skalliga eller icke-skalliga.

Min bestämning av den fiktiva kunskapens omfång och stadga - "Hela sanningen och ingenting annat än sanningen" - är som sagt preliminär. En första revidering tvingar oss att avlägsna den av amerikanska kriminalserier inspirerade frasen "Hela sanningen”. I många fall står det klart för läsaren att hon saknar information som hör till verkets värld $\mathrm{i}$ den meningen att den, likt tillståndet hos madame d'Espards gallblåsa, är kontrafaktiskt åtkomlig, och att den dessutom, till skillnad från nämnda tillstånd, är relevant för en fullständigare förståelse av den värld vi fătt inblick i. Julian Barnes roman The Sense of an Ending kan anföras som exempel. 
Läsaren får successivt följa berättarens rekonstruktion och omtolkning av sitt liv i ljuset av ett brev han fått. Men när boken slutar är inte alla frågetecken uträtade. Modern till en före detta flickvän testamenterar 500 pund och hans vän Adrians dagbok till berättaren - förhållandet till flickvännen tog slut många decennier tidigare, modern har han bara träffat en enda gång, vännen har flera år tidigare tagit sitt liv. Av dagboken får han bara ta del av en utriven sida. Denna sida och annat som sker kastar ett nytt ljus över hans liv, men för läsaren kvarstår frågor (Varför låter kvinnan testamentera honom 500 pund? Vad fanns att läsa i resten av dagboken?) som eventuellt kunde bidragit till förståelsen av Adrians självmord, den f.d. flickvännen beteende, och den döende moderns avsikter. Läsaren undrar över oredovisad relevant information. Med andra ord: hela sanningen har inte presenterats. Detta exempel pekar ut ännu en omständighet, vid sidan av närheten mellan fiktionsläsningens förståelse och försanthållande, som har betydelse får vår känsla av vilken information som hör eller inte hör till fiktionsvärlden: graden av vikt för vår förståelse av historien och dess poäng.

Ytterligare ett fall kan ge än mer skärpa och nyans åt detta. Komiska framställningar kräver ibland att vår uppmärksamhet proportioneras så att effekten inte försvagas. I en artikel påvisar jag hur karaktären Pippi Långstrumps komiska uppträdande och de komiska historier hon berättar vanligen är intentionellt oklara ("Pippi”). Framför allt förmenas läsaren besked huruvida Pippi och den intentionella tomhetens komik avser att vara rolig eller ej, men även den mer grundläggande frågan om hon agerar med någon avsikt alls förblir ofta obesvarad. Jag argumenterar i artikeln för att vi inte ska fästa något avseende vid dessa "Leerstellen”. Vi ska inte söka något svar på dessa frågor, och helst ska vi inte ens notera dem, det skulle endast motverka den komiska effekten av Pippis skrönor och practical jokes. I det här fallet skulle svaren i en mening vara relevanta, i en annan ej. Besked om karaktären Pippis bevekelsegrunder hör naturligtvis till kunskapen om den kausala strukturen hos det fiktiva skeendet, men det skulle dra vår uppmärksamhet från den komiska effekten, det vill säga framställningens yttersta syfte. I det första fallet kan vi uttrycka ofullständigheten så att den saknade informationen inte hör till historien, $\mathrm{i}$ det senare att uppmärksamheten av avsaknaden motverkar det retoriska syftet.

Slutsatsen kan därför tills vidare (bestämningen av fiktionens epistemiska grund är alltjämt preliminär) fångas i nyckelfraserna närhet mellan förståelse och övertygelse å den ena sidan, narrativ irrelevans å den andra.

En annan typ av fiktionsfenomen förefaller dock utmana mitt preliminära förslag även efter strykningen orden "hela sanningen": den otillförlitlige berättaren. Ofta används termen för att ange punktvisa brister i berättarens kunskaper och värderingar, brister som den skarpsynte läsaren genomskådar. Det framgår dels att berättaren är otillförlitlig i vissa avseenden, dels vad som döljer sig bakom hans avsiktliga eller oavsiktliga misstag. Denna typ av genomskinlig otillförlitlighet, som kan exemplifieras av Pär Lagerkvists roman Dvärgen, vållar inga problem: läsaren kan utan större svårigheter upprätta verkets giltiga fiktionssanningar. Mer radikal 
otillförlitlighet kan ta sig olika former. Den av berättaren presenterade historien kan med Per Krogh Hansens term ha en "'double story' effect" (237), det vill säga, den kan uppfattas på två oförenliga sätt (Henry James The Turn of the Screw brukar anföras som exempel), och naturligtvis kan mångtydigheten omfatta fler än två alternativ (spelet med fantasi-verklighet och karaktärernas identiteter i Bret Easton Ellis roman American Psycho kan illustrera denna möjlighet). Ytterligare ett slag av otillförlitlighet innebär att läsaren inte skönjer någon möjlig sanning alls bakom orden, berättaren fabulerar helt enkelt, som baron Münchhausen. ${ }^{3}$ Utgör inte berättelser av dessa slag motexempel mot tesen att fiktionsberättelser inte innehåller annat än sanningen? Mycket eller till och med allt berättaren försäkrar är ju oriktigt eller osäkert.

Men tesen om fiktionens sanningsenlighet omfattar inte nödvändigtvis berättarens trovärdighet: tesen hävdar att någonting är sant därför att boken säger det. De radikalt otillförlitliga berättelserna förmedlar åtminstone sanningen att berättaren är otillförlitlig. Om allt han förmedlar saknar trovärdighet och hans framställning är fullständigt ogenomskinlig så är detta den enda fiktionssanning verket bjuder - och den är odisputabel. Den otillförlitliga berättarens framträdande roll i modern skönlitterär prosa innebär en väsentlig litteraturhistorisk förändring i kunskapsmässigt hänseende såtillvida att kvantiteten säker kunskap i många fall drastiskt minskar. Men fiktionens epistemiska grund förblir densamma: ingenting annat än sanningen.

Det finns emellertid andra skäl att ifrågasätta fiktionssanningens undantagslösa säkerhet. Som jag betonade tidigare, med hänvisningar till David Lewis och Kendall Walton, formar vi fiktionsinnehållet mot olika faktiska fonder, framför allt våra övertygelser om hur världen är beskaffad och vår tro om vad som allmänt hölls (eller hålls) som sant i författarens tid och samhälle. Waltons exempel med läsarna Loretta och Mabel som läser en och samma bok om en man drabbad av en neurologisk åkomma (i Lorettas läsning) eller besatt av djävulen (i Mabels läsning) kan modifieras för visa hur vår fiktiva kunskap kan revideras av textextern information. Låt oss anta att vi vid vår läsning endast noterar hur Andy agerar utan att tolka detta beteende på det ena eller andra sättet. När vi senare studerar medicin eller historia minns vi vad vi läst och drar slutsatsen att karaktären Andy lider av en viss neurologisk sjukdom eller är besatt av djävulen. Vi lägger till något till vår tidigare läsning. Eller, låt oss anta att vi låter Andy lida av en sjukdom, detta mot bakgrund av våra medicinska insikter, och att vi senare, efter att ha studerat etnologi och kulturhistoria lär oss att han från en med verket samtida synpunkt var besatt av djävulen. Låt oss vidare anta att vi som följd av denna kunskap kommer till slutsatsen att denna senare tolkning $i$ högre grad är giltig än vår tidigare anakronistiska medicinska läsning. Vi reviderar vår tidigare tolkning och förkastar delar av den.

3 Typologier över otillförlitligt berättande, liksom själva bestämningen av begreppet narrativ otillförlitlighet, innehåller vanligen fler aspekter än de som är relevanta här - se Krogh Hansen! 
Slutsatsen att våra fiktionsläsningar varken är immuna mot kompletteringar eller mer genomgripande omprövningar upphäver ändå inte gränsen mellan fiktiv och faktisk tillägnelse. En historisk framställning likalydande med fiktionsberättelsen om Andy skulle kunna lida av betydligt allvarligare kognitiva skavanker. Redogörelsen för Andys fysiska beteende skulle kunna vara fabricerad, ja, själva karaktären Andy skulle kunna vara ett påhitt. Och denna skillnad är av största betydelse för ett ämne jag aviserat $\mathrm{i}$ inledningen: förhållandet mellan mina fiktionsepistemologiska slutsatser och narrativ omedelbarhet.

Först en kort terminologisk digression. Med termen "omedelbar" (eller "direkt”) avser jag information utan teckenförmedling, som sinnesförnimmelser och tolkning av och slutsatser från sinnesförnimmelser. ${ }^{4}$ Naturligtvis är berättelser förmedlade, av ord, bilder eller någon annan teckentyp, men termen "narrativ omedelbarhet" ska fattas i figurlig mening. En överordnad narratologisk tes jag tror är riktig är den att narrativ omedelbarhet utmärker berättelsereception i allmänhet. Läsare, lyssnare och åskådare erfar sig som (med betoning på "som”) i direkt kontakt med det framställda skeendet. Narrativ omedelbarhet varierar naturligtvis i intensitet från genre till genre, från text till text, från passage till passage, från läsare till läsare och, för en och samma läsare av ett och samma verk, från läsning till läsning. Min avslutande frågeställning förutsätter emellertid inte att tesen om narrativ omedelbarhet är riktig - tesen finns i bakgrunden av resonemanget och spelar där rollen av en motivering av mitt intresse för frågan. De flesta narrativa teoretiker är dock överens om att åtminstone somliga berättelser - och somliga typer av berättelser - har effekten att dra in läsaren i den gestaltade historien. Med tanke på den som endast skriver under på denna mer anspråkslösa tes om omedelbarhet kan den fråga jag vill ställa formuleras: är den fiktiva kunskapens karaktär på något sätt relevant för upplevelsen av omedelbarhet?

Fiktionssanningar har stabilare grund än motsvarande sanningar uttryckta i faktaframställningar, och en stor del av dem accepterar vi helt. Vi betvivlar inte att Sancho Panza sitter på en åsna, men vi är mindre säkra inför påståendet att Frankrikes president Hollande sitter på en stol gjord av björk. I verkligheten kräver vi textoberoende evidens, i romanen Don Quijote är texten bevis nog. Det slag av information i verkligheten som detta mest liknar är direkt, icke medierad, information, våra sinnens vittnesbörd. För det mesta litar vi till vad vi ser och hör, och när förmedlad information kommer i konflikt med våra perceptioner ger vi de senare vanligen utslagsrösten. Men det inträffar också att vi reviderar och förkastar och, naturligtvis, kompletterar vår sinneskunskap. Revision och förkastelse sker vanligen när vår relevanta bakgrundskunskap har förändrats, på ett liknande sätt som kan ske vid vår fiktionsläsning.

Emellertid tillkommer ytterligare en dimension av omedelbarhet. Krogh Hansen

4 För diskussioner och tillämpningar av tesen om omedelbarhet eller direkthet, se Rossholm "Now's the Time", "Koherens och direkthed", "Fictionality and Information", "Mimesis as Directness" och "Narrative as Story Representation". 
redogör för olika läsningar Nabokovs roman Lolita. Enligt den nutida standardläsningen är berättaren Humbert otillförlitlig, vilket bland annat visar sig av att hans bild av flickan Dolores - en "nymfett" - domineras av hans pedofila projektioner. Krogh Hansen visar hur flera danska litteraturhistoriker för ett drygt decennium sedan till stora delar instämmer i berättarens syn, det vill säga de uppfattar inte Humbert som otillförlitlig, i alla fall inte detta avseende (238). Liksom i Waltons exempel får vi här två motstridiga läsningar, och situationen har likheter med oförenliga versioner av omedelbart uppfattande. Två personer möter en tredje ansikte mot ansikte och får helt olika intryck - som otillförlitlig respektive tillförlitlig. Denna direkta uppfattning motsvarar alltså läsaren metaforiskt talat direkta förnimmelse av en närvarande (fortfarande naturligtvis i metaforisk mening) berättare eller berättarröst. Omedelbarheten har skiftat nivå. Dessutom kan läsaren ställa om sin optik så att det berättade skeendet kommer i direkthetens fokus. För att avgöra i vilken utsträckning detta växelspel kan utvecklas till en i sträng mening samtidig dubbelperception krävs empirisk uppfinningsrikedom. Om "samtidig" tas i mer ungefärlig betydelse förefaller det mig emellertid uppenbart att vi kan höra (metaforiskt talat) Münchhausens skroderande stämma samtidigt som vi ser (metaforiskt) honom lyfta sig själv och sin häst ur ett kärr genom att dra sig i hårpiskan. Och detta avslutande exempel ger också vid handen att den omedelbara receptionen inte begränsar sig fiktionsvärldens sanningar - vi vet ju att Münchhausen ljuger.

\section{LITTERATURLISTA}

Dolezel, Lubomir. Heterocosmica. Fiction and Possible Worlds. Baltimore, London: The John Hopkins University Press, 1998.

Ingarden, Roman. Das literarische Kunstwerk. Eine Untersuchung aus dem Grenzgebiet der Ontologie, Logik und Literaturwissenschaft. Halle: Max Niemeyer, I93I.

Ingarden, Roman. Det litterära konstverket (övers. M. Kinander). Lund: Bo Cavefors förlag, I976.

Kotatko, Petr. "Who is Who in the Fictional World". Fictionality-Possibility-Reality. Red. P. Kotatko, M. Pokorny \& M. Sabates. Bratislava: aleph. 20I0. 89-Ioo.

Krogh Hansen, Per. "Reconsidering the unreliable narrator". Semiotica I65-I/4, (2007): 227-247.

Lewis, David. "Truth in Fiction”. Philosophical Papers vol. I. Oxford, NY: Oxford University Press, 1983 [I978]. 26I-280.

Rossholm, Göran. "Now's the Time: the Fiction Reader's Temporal Perspective”. Essays on Fiction and Perspective. Red. G. Rossholm. Bern \& New York: Peter Lang, 2004. I99-22I.

Rossholm, Göran. ”Koherens och direkthet”. Tidskrift för litteraturvetenskap 3-4 (2004a): XX-XX. Rosshom, Göran.”Fictionality and Information” Fictionality-Possibility-Reality. Red. P. Kotatko, M. Pokorny \& M. Sabates. Bratislava: aleph, 20I0. I9-3I. 
Rossholm, Göran. "Pippi och den intentionella tomhetens komik". Otryckt och omtryckt. Pippis intentioner, Strindbergs perspektiv, Becketts kombinationer och Hans nådes tider. Red. A. Cullhed, C. Johansson \& B. Westin. Stockholm/Stehag: Symposion, $2010 a$.

Rossholm, Göran. "Mimesis as Directness" Mimesis: Metaphysics, Cognition, Pragmatics. Red. G. Currie,

P. Kotatko \& M. Pokorny. London: College Publications, 20I2. I4-39.

Rossholm, Göran. (20I2a) "Narrative as Story Representation". Disputable Core Concepts in Narrative

Theory Red. C. Johansson \& G. Rossholm. Bern \& New York: Peter Lang. 2012a. 183-199.

Ryan, Marie-Laure. Possible Worlds, Artificial Intelligence, and Narrative Theory. Bloomington: Indiana

University Press, I99I.

Ryan, Marie-Laure. "Possible-Worlds Theory". Routledge Encyclopedia of Narrative Theory. Ed. D.

Herman, M. Jahn \& M.-L. Ryan. New York \& London: Routledge, 2005.

Walton, Kendall. Mimesis as Make-Believe. On the Foundations of Representational Arts. Cambridge, Mass. \& London: Harvard University Press, I990. 